\title{
Isolation, Characterization \& Phytochemical Screening, Analytical Method Development and Validation for the Determination of Catechins in B.ciliata by RP HPLC Method
}

\author{
NDVR Saradhi ${ }^{\star 1}$, N Madan Gopal ${ }^{1}$, C Madhusudhna Chetty ${ }^{1}, K_{\text {S Sushmitha }}{ }^{1}$ \\ ${ }^{1}$ Santhiram college of Pharmacy, NH - 40, Nerawada, Kurnool Dist, Andhra \\ Pradesh, India
}

\begin{abstract}
Ayurveda, an ancient system of medicines detailing a number of medicinal plants and their activities in human or animals. The present research work was aimed to develop an analytical procedure for the determination of catechins in the selected plant - B.Ciliata. It is famously known as stone flower/ stone breaker having various biological activities like anti urolithiatic, antiviral, antidiabetic antitumor and cardio protective activity. The methanolic extract of the plant is isolated and a method is developed by using RP HPLC for the determination of catechins in the crude plant extract using a $\mathrm{C}_{18}$ column $(200 * 4.6 \mathrm{~mm}, 5 \mu)$ and detected at $241 \mathrm{~nm}$. The method is validated for its system suitability, Linearity, Accuracy, Precision, Robustness and sensitivity as per the ICH guidelines Q2(R1) to meet the analytical procedure in academic and industrial usage ${ }^{19}$.
\end{abstract}

Key words : B.Ciliata, RP HPLC, Catechins, phytochemical Screening etc.

\section{Introduction:}

The B.Ciliata is one of the medicinal Plants discussed in the Ayurveda system of medicine ${ }^{1,2}$. The plant even though old but having many activities of it now days the usage of the plant leaves and roots is more. B.Ciliata is belongs to Saxifragaceae is a perennial herb. The Catechins are the phytochemicals having antioxidant, antimicrobial activity and used in kidney ailments. The earlier literatures revelas that there are only few methods which have been enlisted in the method development of catechins in various plants. There was no study conducted in the estimation of catechins in B.Ciliata with the selected stationary and Mobile Phases. The fresh leaves and rhizomes were collected from the Nandyal and its surroundings which were authenticated from the Senior Botanist Dr V J Sailaja Rani. The plant parts were shade dried and extracted with methanol, from the pure extract the RP HPLC method is developed for the estimation of catechins ${ }^{3-7}$. The plant leaves and rhizomes are shown in figure -1 .

NDVR Saradhi et al /International Journal of PharmTech Research, 2020,13(2): 18-24. 


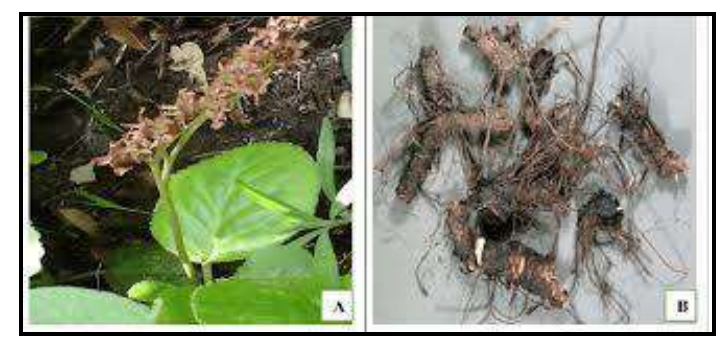

\section{(a) Leaves of B.Ciliata (b) dried roots of B.Ciliata}

\section{Experimental:}

\section{Materials and Methods:}

The chemicals used in the method were HPLC grade and Analytical Grade and their percentage of purity between $99.98-100.02 \%$. chloroform, methanol, ethanol, Acetone, Distilled water. The pure form of the catechin was a gifted sample from the Hi Q laboratory, Hyd. The glass ware like sohxlet apparatus, volumetric flasks, beakers, round botton flaks used for extraction and other procedural activities is Borosil grade. The equipments are calibrated before the experiment electronic balance - Shimazdu (ATY240), Ultrasonicator, Double Beam spectrophotometer - Shimazdu (UV- 1800), HPLC - Analytical technologies (2230) powered

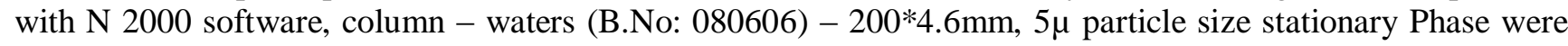
used for the experiment.

\section{Plant Extraction:}

The shad dried leaves were grounded to a fine size and sieved through No: 44, powder was packed in a muslin cloth and adjusted to a position of $3 / 4$ th level of sohxlet apparatus. In a $250 \mathrm{ml}$ of round bottom flask, was added about $200 \mathrm{ml}$ of methanol and made hot percolation was continued for 3 Hours, cooled the flask and make the crude extract was concentrated into solid on a rotary evaporator. The flakes of the crude drug was collected and stored in a SS bottle $e^{6,7}$.

\section{Mobile Phase:}

An equal portion of the HPLC Grade methanol and Chloroform (50:50 v/v) into a flask, filtered through a $0.25 \mu$ membrane filter, subjected for the vaccume filtration, the filtered diluent is collected and sonicated for 10 minutes to remove any air traps in the mobile phase. This is stored in a Borosilcate glass bottle for further use. This is termed as diluent ${ }^{8,9}$.

\section{Standard solution preparation:}

Pure catechin is weighed about $10 \mathrm{mg}$ into clean volumetric flaks and make upto the mark with diluent. The further dilutions were made to get $3 \mathrm{ppm}$ of $\operatorname{catechin}^{10,11}$,.

\section{Sample solution preparation:}

An equivalent amount about $10 \mathrm{mg}$ is taken into $10 \mathrm{ml}$ volumetric flask and diluted upto the mark, further dilutions were made to get approximately $3 \mathrm{ppm}$ of sample solution ${ }^{12-15}$.

\section{Phytochemical Screening:}

General tests were performed for both standard and sample solutions for the identification of various phytochemicals. The test performed for carbohydrates, fats, proteins, alkaloids, glycosides, resins and tannins. Both show a positive results for tannins and further identification test conducted for identification of tannins by bromine water test and match stick test which showed and confirmed the presence of catechins in the plant extract $^{14}$. 
A TLC method is used for the separation of catechins from the crude plant extract. A pre coated TLC silica gel 60 F254 aluminium sheet is used as a stationary phase and methanol: water: chloroform (35:10:65 v/v) is a mobile phase. The sample and standard applied on the plate and eluted for 20 minutes. The plate was dried and sprayed with $0.55 \%$ vanillin in a $4 \%$ Hydrochloric acid. The spots were scrapped and dissolved in the methanol. Now this solution is measured for the absorbance to quantify the catechin present in the sample solution.

\section{Measurement of Lambda Max:}

A spectrum plotted using diluent as blank to the sample and standard solutions both are shown their lambda max at $241 \mathrm{~nm}$. The figure 2 represented as:

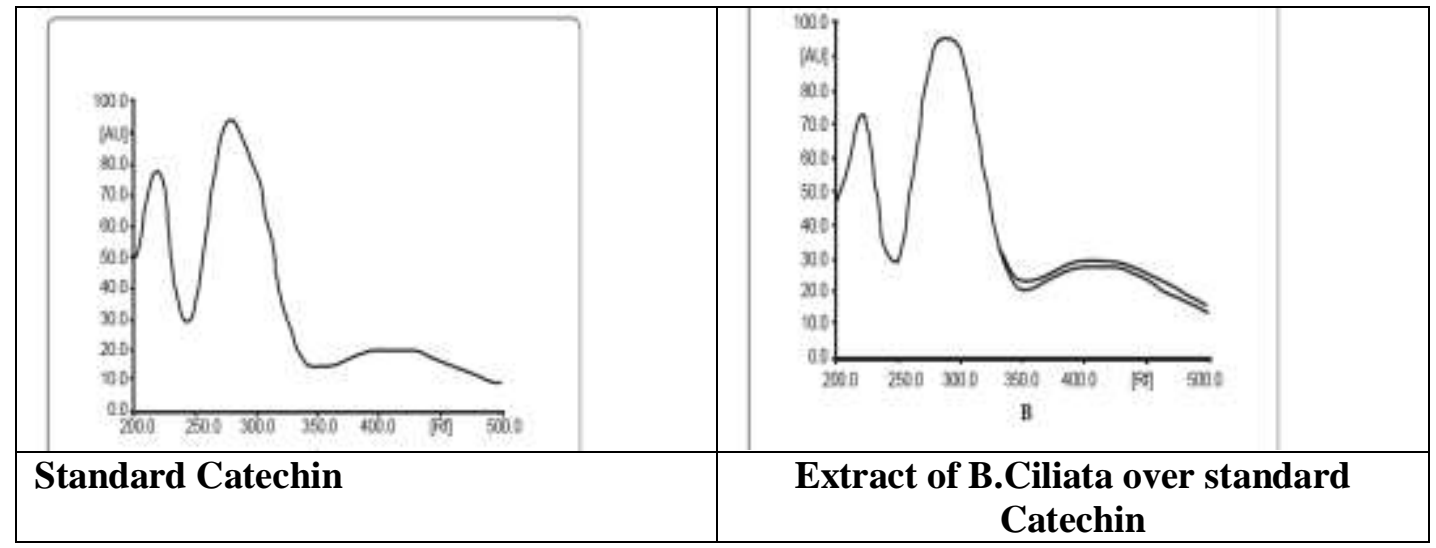

\section{Results and Discussion:}

Various trails have been conducted by changing the column conditions, mobile phase concentrations and UV detection wavelengths. The final optimized method developed by using Hyper chrome ODS- BP $(200 * 4.6 \mathrm{~mm}, 5 \mu)$ column with methanol: chloroform in 1:1 ratios, the flow rate maintained at $1 \mathrm{ml} / \mathrm{min}{ }^{16-18}$. The chromatograms of the placebo, sample and standard were shown in figure $-3,4,5$.

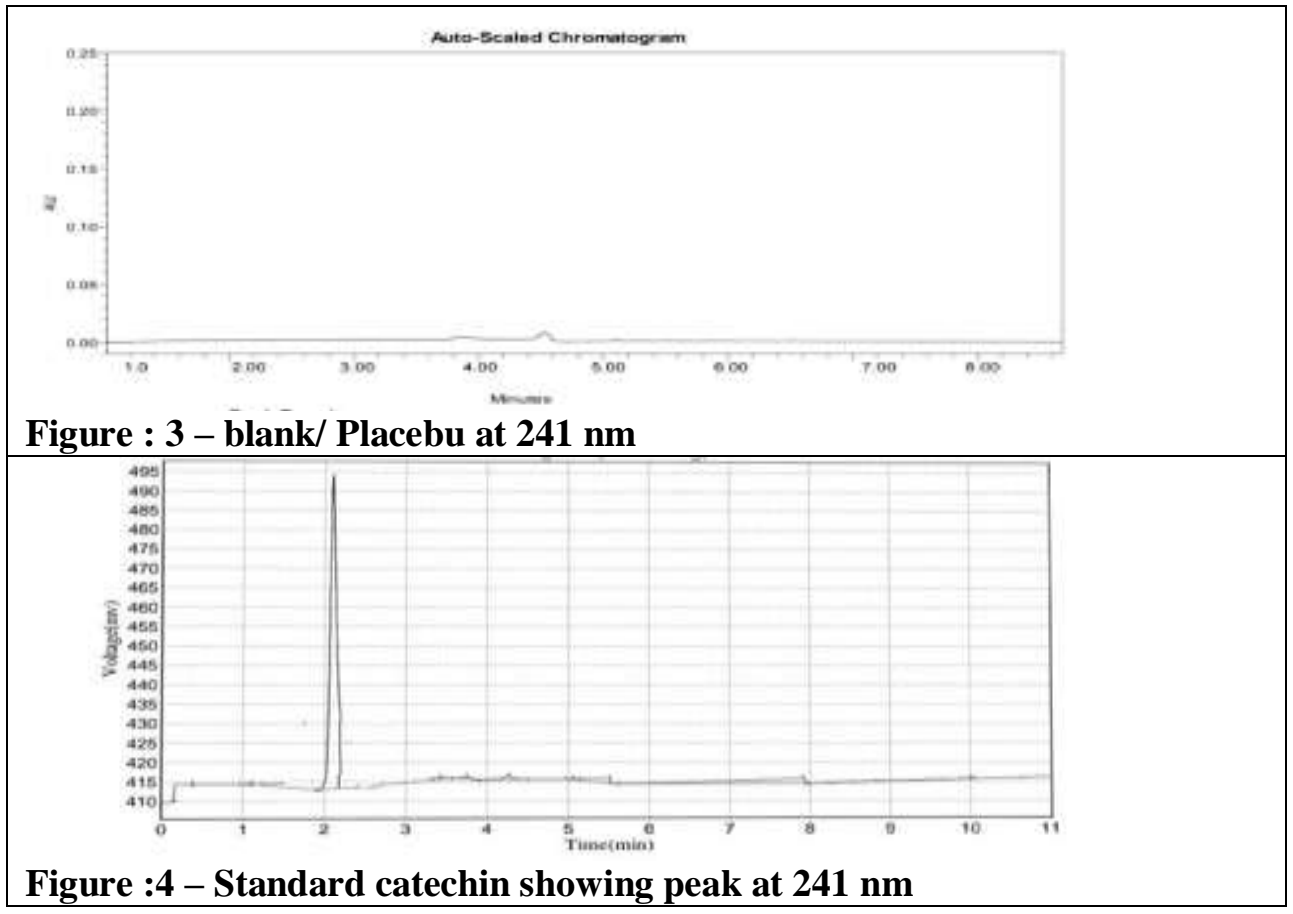




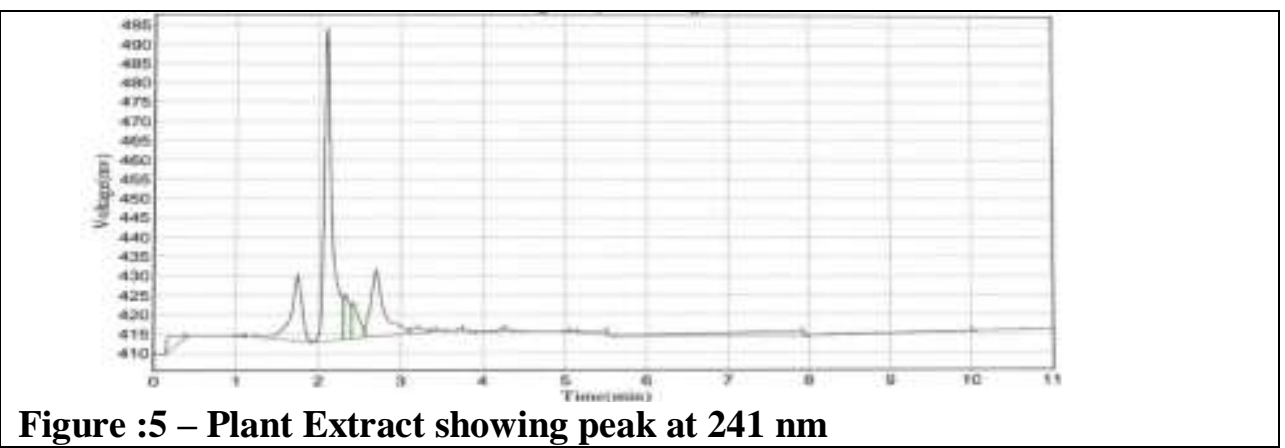

\section{Validation of the method:}

The method was validated various parameters per ICH guidelines Q2(R1) ${ }^{19}$.

(a) System suitability: This procedure validates that the selected procedure for the estimation of the catechin in B.Ciliata by using the HPLC conditions. A replicate injection of same concentration of the catechin standard is injected into the system and measure the peak area, mean, SD, \%RSD was calculated. The results were shown in table -1 .

(b) Linearity: Linearity or range is a measure of analytical procedure that the selected method is suitable for the least to maximum concentrations. The selected procedure is followed for beer lambart law. From the standard primary stock solution 1-5 $\mathrm{ml}$ was taken into individual volumetric flask and diluted with diluent to get $1-5 \mathrm{ppm}$. The peak response was measured for the individual concentration. The correlation between the individual concentrations was shown as in figure -6 .

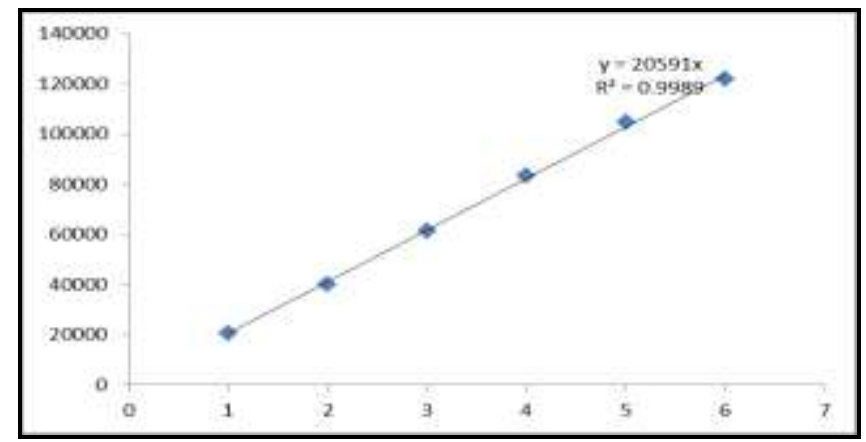

Figure 6: Linearity graph of catechin

(c) Precision: It is the agreement between individual test results with the procedure applied. The precision is completed in 3 steps. Repeatability, intermediate precision, reproducibility. The procedure involves the replicate injection of the same concentration of the sample injected to the HPLC, the peak area was noted between the days, analysts, instruments, and laboratories etc. the results were shown in the table -1 . 
Table 1: System suitability \& precision data for catechin

\begin{tabular}{|c|c|c|c|c|c|c|}
\hline \multirow{2}{*}{$\begin{array}{l}\text { Injection } \\
\text { Number }\end{array}$} & \multirow{2}{*}{$\begin{array}{l}\text { Concentration } \\
\text { in PPM }\end{array}$} & \multirow{2}{*}{$\begin{array}{l}\text { System } \\
\text { Suitability }\end{array}$} & \multicolumn{4}{|l|}{ Precision } \\
\hline & & & Repeatability & $\begin{array}{l}\text { Intermediate } \\
\text { Precision }\end{array}$ & $\begin{array}{l}\text { Analyst } \\
\text { variation }\end{array}$ & $\begin{array}{l}\text { Instrument } \\
\text { variation }\end{array}$ \\
\hline 1 & 3 & 61587 & 61587 & 61597 & 61483 & 60823 \\
\hline 2 & 3 & 61498 & 67570 & 61591 & 61532 & 59878 \\
\hline 3 & 3 & 61481 & 61581 & 61599 & 61345 & 61233 \\
\hline 4 & 3 & 61594 & 61594 & 61590 & 61563 & 60384 \\
\hline 5 & 3 & 61595 & 61595 & 61596 & 61423 & 61482 \\
\hline 6 & 3 & 61497 & 61597 & 61587 & 61082 & 62383 \\
\hline \multicolumn{2}{|c|}{ Mean } & 61542 & 61587 & 61595 & 61404 & 61030 \\
\hline \multicolumn{2}{|c|}{ Standard Deviation } & 55.172 & 10.36 & 3.76 & 176.31 & 879.0 \\
\hline \multicolumn{2}{|c|}{$\%$ RSD } & 0.089 & 0.01 & 0.006 & 0.287 & 1.440 \\
\hline \multicolumn{2}{|c|}{ ICH Criteria } & $>2$ & $>2$ & $>2$ & $>2$ & $>2$ \\
\hline \multicolumn{2}{|c|}{ Test Result } & Passes & Passes & Passes & Passes & Passes \\
\hline
\end{tabular}

(d) Accuracy: It is a validated protocol for the measure the exactness of the experimental procedure. There are two ways for determining the accuracy comparison to a reference method, recovery of the analyte spiked into a blank matrix and standard addition of the analyte. This can be done by taking 3 different concentrations of the sample and injected to the HPLC system, measure the peak area of the each concentration and calculate the percentage of recovery from each level of concentration. The results were shown in table -2 .

Table No 2: Accuracy data of Catechin

\begin{tabular}{|c|c|c|c|c|c|}
\hline S. No & Accuracy Level & Area & Spike added in mg & Recovered in mg & \% Recovery \\
\hline 1 & \multirow{3}{*}{$50 \%$} & 31216 & 1.5 & 1.52 & 101.35 \\
\hline 2 & & 30682 & 1.5 & 1.49 & 99.62 \\
\hline 3 & & 30429 & 1.5 & 1.48 & 98.80 \\
\hline 4 & \multirow{3}{*}{$100 \%$} & 60394 & 3.0 & 2.93 & 98.04 \\
\hline 5 & & 60297 & 3.0 & 2.96 & 97.88 \\
\hline 6 & & 62199 & 3.0 & 3.09 & 100.97 \\
\hline 7 & \multirow{3}{*}{$150 \%$} & 91899 & 4.5 & 4.01 & $\begin{array}{l}99.46 \\
\end{array}$ \\
\hline 8 & & 92385 & 4.5 & 4.52 & 99.99 \\
\hline 9 & & 92899 & 4.5 & 4.51 & 99.99 \\
\hline
\end{tabular}

(e) Robustness: It is a measure of the capacity of the developed method. The procedure involves the change in the system conditions like column flow rate, temperature, detection wavelength etc. the results were tabulated in -3 .

\section{Table 3: Robustness data of Catechin}

\begin{tabular}{|c|c|c|c|}
\hline Parameter & Mean retention time & Mean area & \% RSD \\
\hline \multicolumn{4}{|c|}{ Change in detection wave length (nm) } \\
\hline 237 & 2.09 & 61488.6 & 0.0095 \\
\hline 241 & 2.09 & 61586.6 & 0.0080 \\
\hline 245 & 2.09 & 61738.6 & 0.0195 \\
\hline \multicolumn{4}{|c|}{ Change in Flow rate (ml/Min) } \\
\hline 0.9 & 2.0736 & 55435 & 0.0075 \\
\hline 1.0 & 2.0946 & 61594 & 0.0048 \\
\hline 1.1 & 2.1254 & 67755 & 0.0055 \\
\hline
\end{tabular}


(f) Sensitivity: The sensitivity of the experiment can be calculated by LOD/LOQ of the validation parameters. The LOD is the lowest limit of quantity to be determined using developed procedure. LOQ is the highest minimum limit of quantity to be determined by using the procedure ${ }^{20}$. They were theoretically calculated using linearity graph for its signal to noise ratio and the results shown in the table - 4 .

Table 4: Sensitivity data of Catechin

\begin{tabular}{|l|l|l|l|l|}
\hline Name of the Drug & Slope & SD & LOD & LOQ \\
\hline Catechins & 20591 & 55.172 & $0.0088 \mu \mathrm{g} / \mathrm{ml}$ & $0.0267 \mu \mathrm{g} / \mathrm{ml}$ \\
\hline Acceptability & & & $<3.0$ & $<10$ \\
\hline
\end{tabular}

\section{Conclusion:}

The method initiated with methanol extract, isolation and phytochemical screening and there by HPLC method development. The instruments and chemicals used for the purpose is calibrated and fine graded suitable for the analysis through HPLC. The method developed is validated as per the ICH guidelines of Q2R1 for its system suitability, Linearity, Precision, Accuracy, Sensitivity and robustness to meet the academic and industrial needs.

\section{Acknowledgements:}

Special thanks to santhiram college of Pharmacy for providing all facilities in the laboratories for the new analytical method development for the estimation of catechins in B.Ciliata by RP HPLC method.

\section{References:}

1. S. S. Gurav, A comprehensive Review: Berginia Ligulata wall-A controversial clinical candidate, International Journal of Pharmaceutical Science and Research, 2014, 5(5), 1630-42.

2. KM. Ruby, Jaya Dwivedi, Rajani Chauhan, Berginia ciliata mine of medicinal properties; A Review, International Journal of Pharmaceutical Sciences, 2012, 15(2), 20-23.

3. Anne. Hagerman, Extraction of tannins from fresh and preserved leaves. Journal of Chemical Ecology, 1998, vol.14(2).

4. Gangwal. A, Extraction, and Estimation and TLC of tannins: A Review, International Journal of Pharmaceutical Sciences, 2013, vol.2 (3) 1585-1588.

5. Trupti P. Durgawale, Pratik P. Durgawale and Chitra C. Khanwelkar: Quantitative estimation of tannins by HPLC. Scholars research library, 2016, 8(3); 123-126.

6. Chavan U. D, and Amarowicz, R. effect of various solvent systems on extraction of phenolics tannins and sugars from beach pea, International Food Research Journal, 2013, 20(3); 1139-1144.

7. Sabri Fathima Zohara, Belabri Meriem, Sabri Samira, Alsayadi Muneer M.S. Phytochemical screening and identification of some compounds from Mallow, 2012, 2(4):512-516.

8. Nishi Srivastava, Amit Srivastava, Sharad Srivastava, simultaneous quantification of Berginin, Epicatechin, (+)-Catechin, and Gallic in Bergenia ciliata using HPLC, Journal of Liquid Chromatography and related Data, 2015, 38: 1207-1212.

9. A.K.S.Rawat,D.PSingh, S.K.Srivastava,R.Govindarajan. HPLC determination of Bergenin in different Bergenia species, ACTA Chromatographia, 2007, \{19\}246-252

10. Jingyuanwen, Danhuili, Nataly, Marizlini, Development of an isocratic HPLC method for catechin quantification and its application to formulation studies, ELESVIER, 2012, 83, 1267-7.

11. Attlia Felinger, Barbola Boros, Silvia Jakabova. Validated HPLC method for simultaneously quantification of Bergenin, Arbutin, and Gallic acid in leaves of different Bergenia species, SPRINGER PLUS, 2014, 77(17-18), 1129-1135.

12. Masood Shankhan, Washim khan, Wasim Ahmad Mhareer Singh, Berginin determination in different extracts by HPLC densiometry, Journal of Pharmacy and Bioallied Sciences, 2015, 7(4): 272-274. 
13. Surya Prakash Gupta, Gopal Gang, Quantitative estimation of gallic acid and tannic acid in bhuvnesvara vati by RP-HPLC, scholars research library, 2014, 6(2):31-36.

14. Patel Madhavi G., Patel Vishal., Patel Rakesh K., Development and Validation of Improved RP-HPLC method for Identification and Estimation of Ellagic acid and Gallic acid in Triphala churna. International Journal of Chem tech Research, 2010, 2(3), 1486-1493.

15. Purnima J Ganjage, Amit S Tapkir, Sanjay U Nipanikar, Pawar, Development and validation of a RPHPLC method for the determination of ellagic acid in Terminalia bellirica extract and single herb capsule of Terminalia bellirica. International journal of pharmaceutical education and research, 2018, 52(4): S56-S62.

16. Nikita Sanghavi, S.D. Bhosale, Yashwant Malode, RP-HPLC method development and validation of quercetin isolated from the plant Tridax procumbence L. Journal of scientific and innovative research, 2014;3(6):594-597.

17. Traudi klein, Renata Longhini, Joao Carlos Palazzo de Mello, Development of an analytical method using RP-HPLC-PDA for a semi purified extract of Paullinia cupana var. sorbilis. ELSEVIER, 2012, 502-506.

18. N. Madana Gopal1, C.Sridhar, RP-UPLC Method for Simultaneous Estimation of Sacubitril and Valsartan in Its Bulk and Tablet Dosage Form with Force Degadation Studies. /International Journal of ChemTech Research, 2017,10(4): 279-287.

19. ICH Harmonised Tripartite Guideline, Validation of analytical procedures: Text and methodology, Q2 (R1), International Conference on Harmonization, Geneva. 2005; 1-13.

20. Vijay Kumar Rekulapally, Sripal Reddy Palavai, Raghunadha Reddy Seelam, International Journal of Advances in Pharmacy and Biotechnology,2018, 4(1), 10-22 